\title{
Identifying Requirements for Consumer-Focused Information Technology Acceptance Research
}

\author{
Domagoj Frank ${ }^{1}$, Marin Milković', Valter Boljunčic ${ }^{2}$ \\ 'University North, Trg dr. Žarka Dolinara 1, 48000 Koprivnica, Croatia \\ 2Faculty of Informatics, Rovinjska 14, 52100 Pula, Croatia \\ E-mail:domagoj.frank@unin.hr,marin.milkovic@unin.hr,valter.boljuncic@unipu.hr
}

\begin{abstract}
This article presents an overview of fundamental theories and models in the area of information technology acceptance research with descriptions of their most important features. Research models that put consumers in focus including Unified Theory of Acceptance and Use of Technology 2 (UTAUT2) and Lazy User Theory (LUT) are discussed in more detail herein. By analysing their features and performance, we extract the requirements that should be fulfilled by the new research model, which would enable consumer-oriented information technology research whereby consumers can select between multiple solutions that fulfil their needs.
\end{abstract}

Keywords: Information Technology Acceptance, UTAUT2, Lazy User Theory

\section{Introduction}

Technology and service acceptance models have been the subject of scientific research from the early days of information systems, with the aim of explaining user behaviour related to information technology. The theoretical models that explain the acceptance of technology developed from the theories in the fields of behavioural psychology and marketing, and though there are certain similarities, there are also significant differences in the explanation of technology acceptance. One of the first models is Rogers' Diffusion of Innovation Theory from 1962 [1], in which he observes the diffusion of innovation in relation to social communication channels between individuals over time. In 1975, in the Theory of Reasoned Action (TRA) [2], Fishbein and Ajzen, unlike Rogers, try to explain and predict the behaviour based on the belief, attitude and intention of an individual. One of the most applicable models - Technology Acceptance Model (TAM) - was defined by Davis in 1989 [3], where he determined two crucial factors: perceived usefulness and ease of use. In 1991, Vessey defined the Cognitive Fit Theory [4] which focuses on the problem of how to create a relationship between the task and problem representation in order to improve performance. In the further course of research, one of the more significant models was presented in 1995 by Goodhue and Thompson, who defined the Theory of Task-Technology Fit [5] in which they consider the degree to which technology helps the user to perform tasks. A newer model under the name Unified Theory of Acceptance and Use of Technology, the so-called UTAUT model, was developed in 2003 by Venkatesh et al. [6]. It combines several previous theories into a more comprehensive and complete model of human behaviour. The UTAUT model holds that the constructs of performance expectancy, effort expectancy, social influence, and facilitating conditions are direct determinants of the intention to use and actual use. The UTAUT model also further defines the moderators that affect one or more constructs: gender, age, experience and voluntariness of use.

The mentioned, but also numerous other theories and models were categorized in more detail by Dwivedi et al. in 2012 [7]. In his further work with Williams, Dwivedi by reviewing literature concluded in 2015 [8] that the Unified Theory of Acceptance and Use of Technology (UTAUT) developed by Venkatesh et al. in 2003 [6], "is widely used in the research of the acceptance and dissemination of technology as a theoretical lens of researchers who carry out empirical research of user intention 
and behaviour," and that up until the moment of their research, the UTAUT model had been quoted over 5000 times. The UTAUT model was created by combining eight of the most significant theories and models in an attempt to create a complete model of user behaviour. In his experiment, on the same set of data, Venkatesh individually compared each of the traditional models and determined that they can explain between $17 \%$ and $53 \%$ of the variance in the user's intention to use information technology, while UTAUT explained $69 \%$ of the variance [7].

During the last ten years, researchers have been shifting their focus from the observation of technology acceptance to the observation of consumers' acceptance of technical appliances, applications and services. Consumers are the users who are responsible for the costs and such costs can be dominant in the acceptance of technology. Furthermore, consumers have previously learned behaviours, i.e. habits, and they often expect that the use of technology gives them satisfaction and pleasure. Venkatesh thus recognizes the need for a further expansion of the original UTAUT model in order to explain the behaviour of users-consumers, and in 2012 he publishes the Unified Theory of Acceptance and Use of Technology 2 , i.e. the UTAUT 2 model [9] with which he improves his initial UTAUT model from 2003 and expands it with three new constructs: price value, habit and hedonic motivation. By comparing the results of the UTAUT and UTAUT2 models on a sample of Hong Kong residents when researching user acceptance and the use of mobile Internet, he concludes that UTAUT2 provides significantly better results in explaining the variance of the user's behavioural intention that influences his or her true behaviour the use of technology - increasing it from 56\% in the case of the UTAUT model to $74 \%$ in the analysis congruent with the UTAUT2 model. For user behaviour, i.e. the real use of technology, UTAUT2 explains $56 \%$ of variance compared to the $40 \%$ explained by UTAUT on the same set of data. In 2015, Rondan-Cataluna et al. [10] compared TRA, TAM, TAM modifications (TAM2 and TAM3), UTAUT and UTAUT2 models and showed that UTAUT2 has a $26 \%$ better power of explaining than the TAM models on the sample of end-users of mobile Internet, i.e. in the consumer context. With it, they confirmed that UTAUT2 has better performances when research is conducted on end users, i.e. consumers.

The UTAUT2 approaches the consumer by looking at only one information technology, i.e. solution, ignoring all other possible solutions that would allow the consumer to meet his or her needs. The mentioned problem and the need for a new approach to the research of customer and consumer behaviour were noticed in 2007 by Collan and Tetard who suggest the Lazy User Theory and refer to their model as the "Lazy User Model" (LUM) [11]. They developed the model in more detail in 2009. [12]. LUM focuses on the user-consumer and looks at all possible solutions that the user can choose between, instead of observing just one solution (i.e. technology), which is how the UTAUT2 model approached the problem. LUM takes into account the needs and characteristics of the user in the solution selection process and the effort which is expected from the user while he or she is selecting the solution for the problem from the set of all possible solutions. The user will most likely choose the solution that requires the least effort. The user's effort to accept technology is also conditioned by the cost of learning and switching from the existing solution to a new one, which includes the time, energy and financial costs that the user has to spend in order to learn to use the solution or to switch to a new solution (product or service).

\section{Basic theories and information system acceptance models}

When developing the Unified Theory of Acceptance and Use of Technology (UTAUT), Venkatesh analysed in detail the theories and models of information system acceptance and selected eight dominant theories and models [6]:

(1) The Theory of Reasoned Action (TRA) that was developed by Fishbein and Ajzen in 1975 [2] stems from social psychology and tries to explain the consequence of the attitude and belief of an individual on his or her behaviour. According to TRA, the behavioural intention sets forward the real behaviour. Behavioural intention is influenced by two constructs: 
attitude towards behaviour and subjective norms. Attitude towards behaviour is the positive or negative feeling of an individual about the accomplishment of targeted behaviour, and it has an evaluational impact on an individual, while the subjective norm reflects the perception of a person about the opinion of the majority of people who are important to him or her when performing the behaviour that is being researched.

(2) Davis' Technology Acceptance Model (TAM) from 1989 [3] was designed to predict the acceptance of information technology at work. TAM is based on the Theory of Reasoned Action (TRA), replacing two constructs: attitude towards behaviour and subjective norms from TRA are replaced with two constructs of technology acceptance: perceived ease of use and perceived usefulness. The construct of perceived usefulness is defined as the degree to which an individual believes that using the system will help him or her improve business performance, while the construct of perceived ease of use is defined by Davis as "the degree to which an individual believes that the use of a certain system would be carried out without any physical and mental effort" [3], page 320 . TAM models that the use of the system is determined by behavioural intention, which is influenced by the attitude towards use and perceived usefulness. The attitude towards the use of technology is the function of the perceived simplicity of use and perceived usefulness. Venkatesh and Davis also take into consideration the TAM2 model [13], which expands the original TAM model with the subjective norm construct taken from TRA and TPB as an additional predictor of intention.

(3) The Motivation Model (MM) is a model in which in 1992 Davis et al. applied the motivation theory in order to understand the acceptance and use of new technology [14]. The constructs he uses are the following: extrinsic motivation, which corresponds to the perception that users will want to carry out the activity because they see it as a means of achieving valuable results that stem from the observed activity, e.g. improved business performance, increased paycheck or a promotion in the company's hierarchy, and intrinsic motivation, which corresponds to the perception that users will want to carry out the activity without any special reason except to perform the activity per se.

(4) Ajzen created the Theory of Planned Behaviour (TPB) in 1991 [15] with the goal of addressing the weaknesses of the Theory of Reasoned Action for cases in which individuals do not have complete voluntary control over their behaviour. He takes the constructs from the Theory of Reasoned Action and adds the construct of perceived behavioural control, which reflects the perceived ease or difficulty in the conducting of behaviour. According to the TPB model, real behaviour is the function of behavioural intention and perceived behavioural control. Behavioural intention is determined by attitude, subjective norm and perceived behavioural control.

(5) Combined TPB/TAM is a hybrid model that combines the predictors from TPB and perceived usefulness from the TAM model [16].

(6) The Model of PC Utilization (MPCU) [17] is a model which was intended in 1991 by Thompson et al. for the use of a personal computer but is in itself adaptable for the anticipation of the use of other information technologies. The model includes the following constructs: job fit, which reflects the belief of an individual that the use of technology will enhance the performance of his or her job, complexity as the perception of how difficult it is to understand and use new technology, longterm consequences that include the outcomes that have a pay-off in the future, affect towards behaviour that includes the feeling of joy, elation or pleasure from one side and depression, disgust, displeasure or hate from the other side associated by the individual with a particular act, social factors that are connected to the culture of the group that the individual belongs to and facilitating conditions that are the objective factors that facilitate the easy performance of an activity.

(7) The Innovation Diffusion Theory (IDT) was defined in 1965 by Rogers [1], and it was adapted for information systems in 1991 by Moore and Benbasat [18] who suggested that adoption speed is affected by the user's perception of the use of innovation instead of the innovation itself, which separates the 
characteristics of innovations in the primary property (such as the cost price) and the secondary property (e.g. perception of costs). For the use of the Theory of Information Diffusion in the Research of Adopting Information Technology, Moore and Benbasat define eight constructs: relative advantage that reflects the improvement degree of a new solution in relation to the old one, compatibility - the perception of solution consistency in relation to the already existing values, needs and past experiences, ease of use, possibility of testing, result demonstrability - the more the innovation is demonstrated and the more visible the advantages are, the more likely it is that it will be adopted, visibility that reflects the individual's observation that others in the organization use the system, voluntariness - the degree to which the use of innovation is seen as voluntary and image, i.e. the degree to which the use of innovation is seen as an improvement of someone's image in his or her social system.

(8) The Social Cognitive Theory (SCT) from 1986 [19], was in 1995 adapted by Compeau and Higgins [20] for the research of computer use.

In addition to the aforementioned theories that were used by Venkatesh in his work [6], Collan and Tetard [12] take into consideration the Task-Technology Fit Theory (TTF) which was in 1995 outlined by Goodhue and Thompson [5]. The model suggests that the fit of the task and technology characteristics leads to an improved performance, arguing that it is more likely that technology will have a positive influence on performance if technology is consistent with the task characteristics. For the measuring of the task and technology fit, they introduce four constructs: task characteristics, technological characteristics, utilization and performance impact.

In 2010, Rocker [21] conducted an analysis of the traditional models and the quality of research that had been conducted on them, and he concluded that in most research, the existing models such as the Model of Technology Acceptance, the Theory of Reasoned Action, or the Theory of Planned Behaviour were able to explain and anticipate acceptance well enough, but that the observed systems were simple and usually consisted of a personal computer with a standard software and a user in a business situation, and that their compliance with the testing of new and future technologies that disrupt time and space constraints was questionable. In 2010, when reviewing 79 empirical research in 73 papers that use the Model of Technology Acceptance, Turner et al. [22] concluded that although it is likely that the behavioural intention of use correlates with real use, the correlation is less likely to exist between the use and independent variables of the perceived ease of use and perceived usefulness, and that the Model of Acceptance Technology should be used carefully outside the area in which it had been confirmed. The Model of Technology Acceptance and its further development were revised in 2007 by Benbasat and Barki [23], who reached a conclusion that the researchers' work on expanding the model to adapt to the changing IT environment led to "a state of theoretical chaos and confusion," where it was no longer clear which of the many versions were commonly accepted. They suggested a revision of the entire model, starting from the Theory of Reasoned Action and the change of independent variables. In 2007 Venkatesh et al. [24] reviewed and compared the main milestones in the research of technology acceptance and observed that there was a great deal of progress in the research of technology acceptance, but that there was still too much focus on the replication of and minor improvements in the existing theories without real progress, and they stated that the focus of research should shift to today's relevant business problems.

\section{Unified Theory of Acceptance and Use of Technology}

In the Unified Theory of Acceptance and Use of Technology (UTAUT), Venkatesh attempts to explain the intention of the user to use the information system, as well as the subsequent behaviour of the user. Moreover, he integrates the theories and models outlined in the Chapter 2 (Figure 1).Three constructs: performance expectancy, effort expectancy and social influence create the behavioural intention to use and thus jointly act on the use, i.e. the use of the observed technology. The fourth construct, facilitating conditions, does not affect the 
intention to use, but directly affects the user's behaviour, i.e. the use. Venkatesh also anticipates four moderators that indirectly influence the behavioural intention and behaviour: gender, age, experience, and voluntariness of use.
Performance expectancy is affected by age and gender, effort expectancy is affected by age, gender and experience, social influence is affected by all moderators, while facilitating conditions are affected by age and experience.

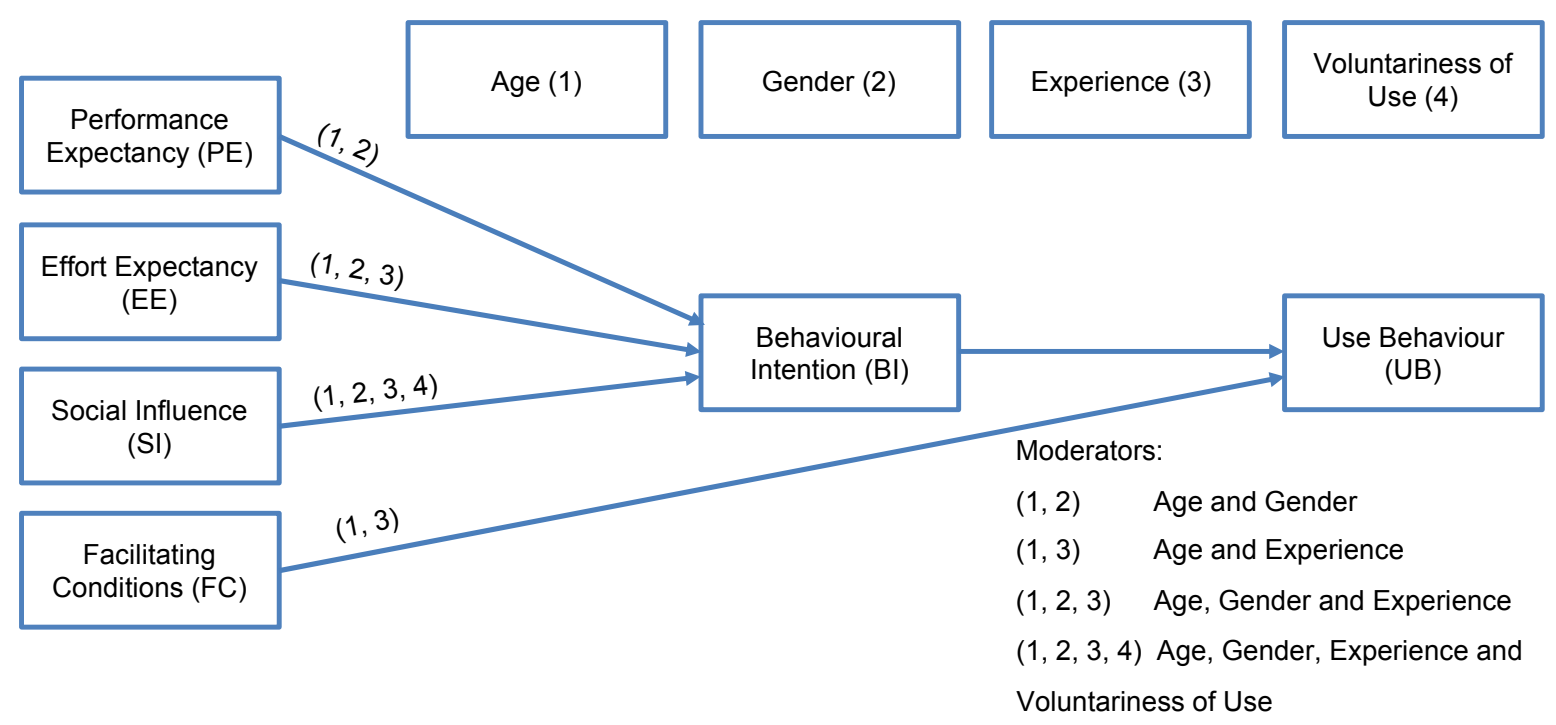

Figure 1. UTAUT Model [6]

The performance expectancy construct describes the belief of the respondents that by using the observed information technology, they will perform their job more efficiently, i.e. be more productive. On the other hand, effort expectancy determines the degree to which the respondents believe that the use of information technology will be difficult; it includes their subjective estimate of the effort needed for a professional use of the information technology. Social influence determines the degree to which the respondents believe that their environment will support the introduction or use of the observed information technology. Facilitating conditions are defined as the "degree to which the respondents believe that there is an organizational and technical infrastructure which supports the use of the system." [6].

\section{Unified Theory of Acceptance and Use of Technology 2}

Venkatesh revised in 2012 the UTAUT model with his associates and added three new constructs that take into account the user-customer aspects and they called it the UTAUT2, i.e. the Unified Theory of Acceptance and Use of Technology 2 [9]. Without any changes, the constructs of performance expectancy, effort expectancy and social influence were taken from the UTAUT model, and a link added between facilitating conditions and the intention to use were added. Venkatesh removed the moderator of the voluntariness of use and retained only three moderators that affect constructs (age, sex, and experience) in UTAUT2.

UTAUT2 introduces three new constructs (Figure 2): hedonic motivation determines the respondent's level of perception on whether the use of new information technology will be enjoyable or fun. Price value reflects the conviction of the respondent that the use of new information technology will be valuable in relation to the cost (e.g. good value for money). Habit determines the respondent's level of certainty that, according to his or her experiences, the use of new information technology will become a routine. 


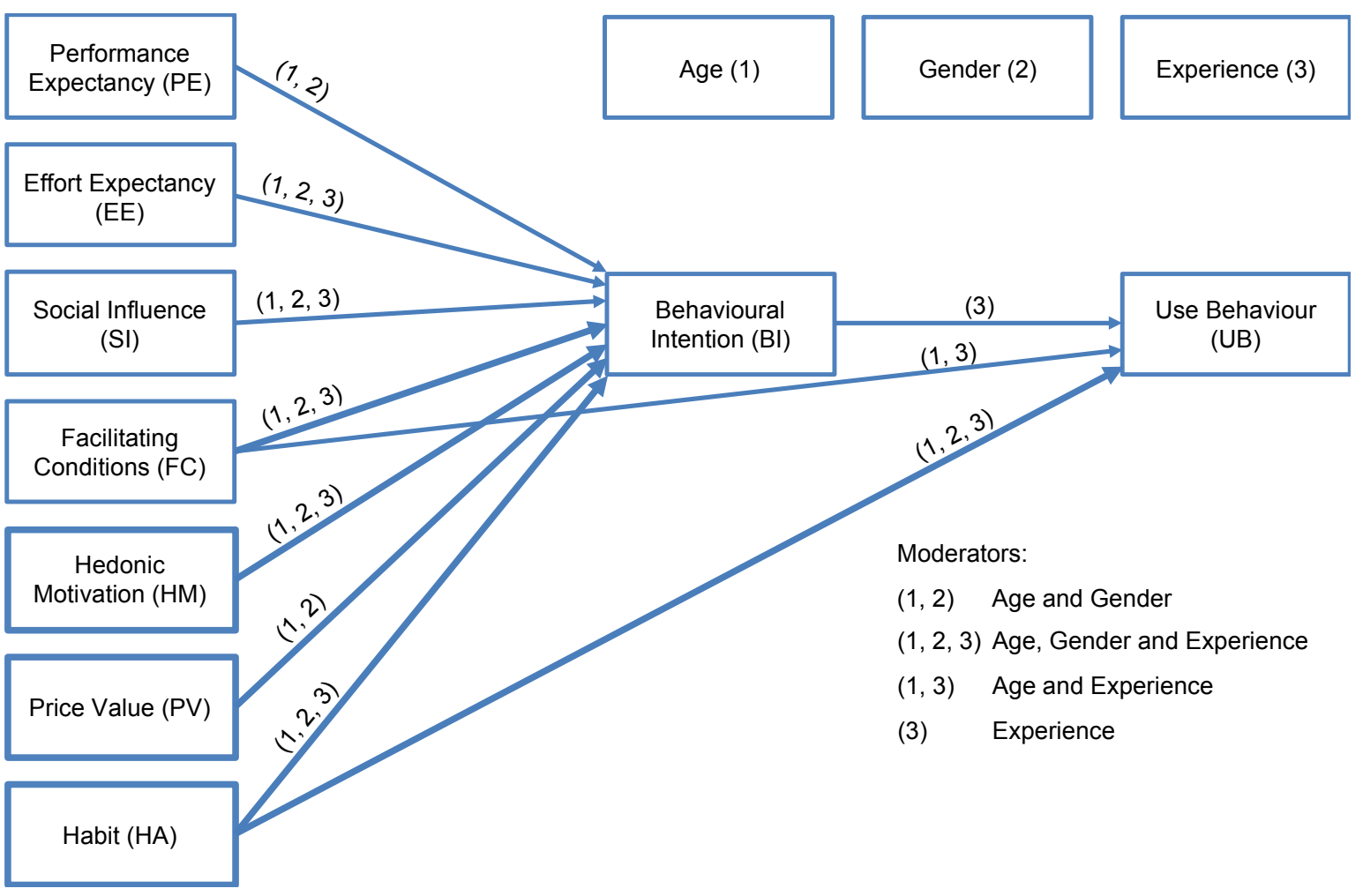

Figure 2. UTAUT2 Model [9]

\section{Lazy User Model}

The Lazy User Model tries to define a framework that allows the research of user behaviour depending on his or her needs on the one hand, and his or her state on the other hand; that he or she, from all possible solutions, will choose a solution based on the principle of the least effort [11, 12].

LUM's focus is on the characteristics and needs of the user, which LUM sees as the most important factors in technology acceptance. According to LUM, the user selects a solution to meet his or her needs from the subset of universal (all possible) solutions, which is limited by the user's state, i.e. the current capabilities and/or circumstances surrounding the user, namely a set of solutions that are available to him or her and are a subset of a universal set of solutions (Figure 3). When choosing a solution, the user valorises the effort he or she assumes will be needed when choosing one of the solutions and selects the one that requires the least effort; namely, LUM suggests that the user automatically applies the path of least resistance and automatically selects the solution that requires the least effort.

Collan and Tetard define user need as a "clearly definable desire that can be fully met," for example in the case of an information nature need: the need for the type, depth, quality and completeness of the information and the speed of retrieving that information. User state refers to the conditions in which the user finds himself or herself when he or she has a need, i.e. needs a particular product or service. Those conditions vary depending on the user's location, available devices, time in which the need should be met, and other resources that

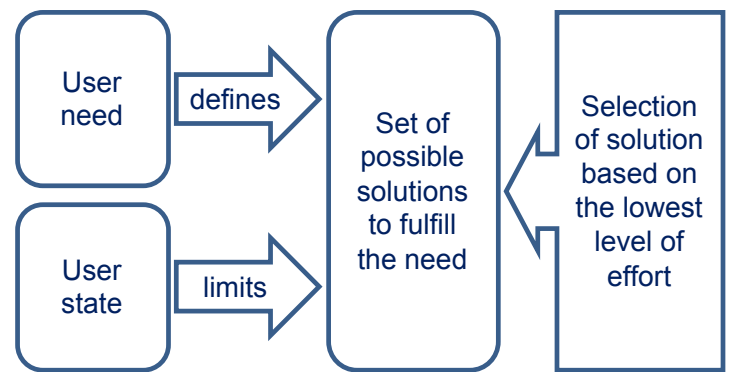

Figure 3. Lazy User Model [12] 
enable the user to act. Depending on the user's state, a subset of solutions from the universal set of solutions is selected and only those that can meet the need in that specific state are retained. Collan and Tetard define effort in the sense that it involves the necessary time, money and energy to perform a physical or mental task. They assume that less is necessary and better, that is, that the user inevitably chooses a solution that requires less money, time or energy spent. It is obvious that there are situations in which the user has to look at multiple factors and that he or she does that in a subjective manner, i.e. that each user has his or her own individual function of transforming those factors when assessing the solution that requires the least effort - the degree of the perception of required effort varies from user to user. Given that the user has to anticipate the level of effort for each solution, and that it is not possible to do that correctly, the user learns with each choice - he or she compares the estimated level of effort with the actual effort and thereby generates a feedback loop of information that increases the accuracy of the choice in future choices. In the boundary case when two or more solutions in user perception require the same level of effort, the selection happens by chance.

The Lazy User Theory introduces switching costs - the cost that a user estimates is generated when one has to decide whether to switch from using one solution to meet his or her needs to another solution. The theory uses the concepts that in 2002 Thompson and Cats-Baril [25] considered in the Information Technology and Management Theory as the cost associated with the change of suppliers. It also considers the work of Hess and Ricart from 2003 that deals with the company's market competitiveness and which says that "the user's switching costs are generally defined as costs that keep users from switching to a rival product or service." [26]. According to Hess and Ricart, the costs arise from the investment that needs to be done in order to use a solution, and that includes software licenses, relationship with the supplier, accumulated knowledge and education, cost of seeking solutions, trust, commitment, and more. Investment may be both a previous and a potential one. When choosing, a customer decides between the previous investments he or she has already made and potential future investments in which he or she is yet to invest, i.e. he or she has to bear a new expense. In order for the user to choose a new solution that requires additional investment, the corresponding return on the new investment must be higher than the benefits that the user enjoys due to the existing investment. Collan and Tetard note that users can also go back to the previously used solution and will, depending on their state and need, choose a solution where the switching costs are minimal. Observing the switching costs helps understand the barriers that prevent users from changing the technology they use for fulfilling their need and from the trigger of change in user behaviour. As part of the switching costs, Collan and Tetard particularly emphasize learning and exercise as important factors, and they recognize four phases in the process of accepting the solution:

1. The phase before use, in which users need the information on the solution - way of use, price, ease of use, experience of others, possible disadvantages and other, and on the basis of that information they build their expectations.

2. First use during which users compare their expectations with the real use, which results in the acceptance or rejection of the system.

3. Early use during which users build their knowledge and experience that lead them toward routine use.

4. Routine use, when users know how to use all the functions they need.

All the mentioned learning phases are an investment that can be partially transferred (for example, if the new system has a similar interface) or may become a "sunk" cost, i.e. a non-refundable cost in the event of a transition to a new solution without returning to the old ways in the future choice of solutions.

\section{Comparison of the characteristics of UTAUT 2 and LUM}

UTAUT is based on the fact that the user can not choose whether to use technology or not, i.e. its purpose is to research the acceptance of information technology in the business 
environment, where information solutions are often determined by the business policy of the company. UTAUT2 puts focus on the end user, i.e. the consumer, by introducing constructs that value motivational factors related to perceived value in relation to cost, habit or enjoyment of using information technology, but it still holds on to observing one possible solution, i.e. the use of one information technology, excluding all other user possibilities with which they could solve their problem or meet their wishes.

The Lazy User Model (LUM) puts users and their needs in the focus and is comprehensive from the point of view of observing the users' action in solving their need - it assumes that users can choose between all the possible solutions that can fully meet their specific need. LUM anticipates that users will always choose the solution that requires the least effort in terms of time, energy, money, and other resources.

UTAUT2 includes the construct of intention in the use of technology as an important factor affecting the real use of technology, while LUM includes the cultural and social circumstances that surround the user and contemplates the impact of the available resources on technology acceptance.

UTAUT2 and LUM have similarities in the factors that impact the use. The Lazy User Model assumes that the general characteristics of users will influence the use, while UTAUT2 classifies the characteristics that impact the use in the categories of age, gender and experience. LUM perceives effort in a broader sense as the key decision-making element in the solution selection process, while UTAUT2 also perceives effort in a narrower sense as the decisive factor of behavioural intention, but it also includes the additional constructs of facilitating conditions, price value and habit, that are also included in "size" of the effort as perceived by LUM. UTAUT also takes into account facilitating conditions, which are very similar to the conditions and circumstances surrounding the user, and which are considered by LUM.

Unlike the UTAUT2 model, on a theoretical level, LUM considers the concepts of effort, switching costs and learning, suggesting a free definition of constructs and relationships among them to the researcher, which makes LUM more of a theory than a research model. Such lack of definition can be the cause of a very small number of research and experiments that use LUM as a research model.

\section{Requirements for the Consumer- Focused Research Model}

In a world where, in order to satisfy their needs, consumers can choose between a number of solutions, the model which could help in the research of consumer behaviour has to put its focus on the user-consumer and their free will to choose the solution that best suits them. At the same time, the model should rigorously determine its constructs in order to define a research framework that allows repeatable measurements. The overview in the previous Chapter shows that none of the existing models alone meet those criteria, but also that UTAUT2 and LUM share features that can be used to create a new model that will meet the required research requirements:

1. The model should enable various user states. Consumer information services are intended for individual use. Technological development has enabled the consumers to consume television content regardless of the location or situation surrounding them. For this requirement, LUM contains concepts that can be adopted.

2. The model has to put focus on the user-consumer. Use of various consumer information services is a voluntary act and the desire to use or consume them is induced by other motivations. The UTAUT2 model has elaborated variables, for example hedonic motivation, price value and habit, which make it possible to cover potential motivations of consumers in high quality.

3. The model should include the voluntariness of use and free choice of the solution that best fits the consumer. The consumer can, in his or her freedom of choice and voluntariness of use, choose any of the solutions that satisfies his or her wishes or needs. To fulfil this requirement, it is necessary to adopt the concepts of solution selection contained in LUM.

4. The model should enable the comparison of different or competing solutions, i.e. 
technologies. The goal is to research the behaviour of consumers in the acceptance of the technology that is being observed. Except in the case of completely new services that have not existed so far, the consumers usually already have ways to satisfy their wishes and needs. Therefore, the model must enable the research of effort in the broader sense of the word when consumers switch from the existing behaviour (technology use) to new behaviour, i.e. the use of the technology that is being observed. LUM is a suitable model for the adoption of concepts that meet this requirement

5. The model should enable the measuring of switching costs that the user must bear in order to switch from the solutions they use currently, to the information solution that is being observed in the research. The idea of this concept is elaborated in LUM, but UTAUT2 defines the variables and connections between them that can be adopted to meet this requirement.

6. The model must enable quantitative and repeatable measurements in order to be used to measure the changes in consumer behaviour in time and also for various solutions. Therefore, it is necessary to rigorously determine the constructs and relations between them, which is the requirement met by UTAUT2.

\section{Conclusion}

In this article we presented an overview of fundamental theories and models in the area of information technology acceptance research. Currently, the most comprehensive and advanced information technology acceptance model is Unified Theory of Acceptance and Use of Technology 2 (UTAUT2), which aggregates the vast body of technology acceptance knowledge and introduces hedonic motivation, price-value and habit variables that aim to enable measurement of user-consumer behaviour. The essential deficiency of the UTAUT2 model is it's focus on the single solution or technology that can be observed, as it is the only available solution to the consumer. The fact that consumers typically have multiple solutions available for their needs is recognised by the Lazy User Theory and the corresponding Lazy User Model (LUM), which see the characteristics and needs of the user as the most important factors in technology acceptance. According to LUM, users select a solution to meet their needs from a set of possible solutions, based on current capabilities they have. When choosing a solution, they select the one that requires the least effort. Despite such an inventive approach that would enable comprehensive technology acceptance research of the consumer behaviour, LUM does not rigorously define variables that should be measured, leaving their definition to each individual researcher. Our analysis shows that the new Consumer-Focused Research Model can be built by merging strong features of both UTAUT2 and LUM models, that would overcome their deficiencies. Requirements for such a new model are presented herein.

\section{Literature}

1. E. M. Rogers, Diffusion of innovations. New York: Free Press, 1962.

2. M. Fishbein and I. Ajzen, Belief, attitude, intention, and behavior: An introduction to theory and research. Reading, MA: Addison-Wesley, 1975.

3. F. D. Davis, 'Perceived usefulness, perceived ease of use, and user acceptance of information technology', MIS Quarterly: Management Information Systems, vol. 13, no. 3, pp. 319-339, 1989.

4. I. Vessey, 'Cognitive Fit: A Theory-Based Analysis of the Graphs Versus Tables Literature*', Decision Sciences, vol. 22, no. 2, pp. 219-240, Mar. 1991.

5. D. L. Goodhue and R. L. Thompson, 'Task-technology Fit and Individual Performance', MIS Q., vol. 19, no. 2, pp. 213-236, Jun. 1995.

6. V. Venkatesh, M. G. Morris, G. B. Davis, and F. D. Davis, 'User acceptance of information technology: Toward a unified view', MIS Quarterly: Management Information Systems, vol. 27, no. 3, pp. 425-478, 2003.

7. Y. K. Dwivedi, M. R. Wade, and S. L. Schneberger, Eds., Information Systems Theory: Explaining and Predicting Our Digital Society, Vol. 2. New York: Springer-Verlag, 2012.

8. M. D. Williams, N. P. Rana, and Y. K. Dwivedi, 'The unified theory of acceptance and use of technology (UTAUT): a literature review', Journal of Enterprise Information Management, vol. 28, no. 3, pp. 443-488, Apr. 2015.

9. V. Venkatesh, J. Y. L. Thong, and X. Xu, 'Consumer acceptance and use of information technology: Extending the unified theory of acceptance and use of technology', MIS Quarterly: Management Information Systems, vol. 36, no. 1, pp. 157-178, 2012. 
Identifying Requirements for Consumer-Focused Information Technology Acceptance Research

10. F. J. Rondan-Cataluña, J. Arenas-Gaitán, and P. E. Ramírez-Correa, 'A comparison of the different versions of popular technology acceptance models: A non-linear perspective', Kybernetes, vol. 44, no. 5, pp. 788-805, May 2015.

11. M. Collan and F. Tétard, 'Lazy user theory of solution selection', in Proceedings or the CELDA 2007 Conference, Algarve, Portugal, 2007, pp. 273-278.

12. M. Collan and F. Tétard, 'Lazy User Theory: A Dynamic Model to Understand User Selection of Products and Services', in Proceedings of the 42nd Hawaii International Conference on System Sciences, (HICSS-42), Big Island, HI, 2009, pp. 1-9.

13. V. Venkatesh and F. D. Davis, 'Theoretical extension of the Technology Acceptance Model: Four longitudinal field studies', Management Science, vol. 46, no. 2, pp. 186-204, 2000.

14. F. D. Davis, R. P. Bagozzi, and P. R. Warshaw, 'Extrinsic and Intrinsic Motivation to Use Computers in the Workplace1', Journal of Applied Social Psychology, vol. 22, no. 14, pp. 1111-1132, Jul. 1992.

15. I. Ajzen, 'The theory of planned behavior', Organizational Behavior and Human Decision Processes, vol. 50, no. 2, pp. 179-211, 1991.

16. S. Taylor and P. A. Todd, 'Understanding Information Technology Usage: A Test of Competing Models', Information Systems Research, vol. 6, no. 2, pp. 144 176, Jun. 1995.

17. R. L. Thompson, C. A. Higgins, and J. M. Howell, 'Personal Computing: Toward a Conceptual Model of Utilization', MIS Quarterly, vol. 15, no. 1, pp. 125143, 1991.

18. G. C. Moore and I. Benbasat, 'Development of an Instrument to Measure the Perceptions of Adopting an Information Technology Innovation, Information Systems Research, vol. 2, no. 3, pp. 192-222, Sep. 1991.

19. A. Bandura, Social foundations of thought and action: A social cognitive theory. Englewood Cliffs, NJ, US: Prentice-Hall, Inc, 1986.

20. D. R. Compeau and C. A. Higgins, 'Application of Social Cognitive Theory to Training for Computer Skills', Information Systems Research, vol. 6, no. 2, pp. 118-143, Jun. 1995

21. C. Röcker, 'Why Traditional Technology Acceptance Models Won't Work for Future Information Technologies', World Academy of Science, Engineering and Technology, vol. 65, pp. 237-243, 2010.

22. M. Turner, B. Kitchenham, P. Brereton, S. Charters, and D. Budgen, 'Does the technology acceptance model predict actual use? A systematic literature review', Information and Software Technology, vol. 52, no. 5, pp. 463-479, 2010.

23. I. Benbasat and H. Barki, 'Quo vadis TAM?', Journal of the Association for Information Systems, vol. 8, no. 4, p. 9, Apr. 2007.

24. V. Venkatesh, F. D. Davis, and M. G. Morris, 'Dead Or Alive? The Development, Trajectory And Future Of Technology Adoption Research., vol. 8, no. 4, p. 21, 2007.

25. R. L. Thompson and W. L. Cats-Baril, Information Technology and Management, 2nd ed. New York, NY, USA: McGraw-Hill, Inc., 2002.

26. M. Hess and J. E. Ricart, 'Managing Customer Switching Costs: A Framework for Competing in the Networked Environment', Mgt Res: J of Iberoamer Ac Mgt, vol. 1, no. 1, pp. 93-110, Apr. 2003. 